\title{
The oncomiR miR-197 is a novel prognostic indicator for non-small cell lung cancer patients
}

\author{
K Mavridis ${ }^{1}$, F Gueugnon ${ }^{2}$, A Petit-Courty ${ }^{2}$, Y Courty $^{2}$, A Barascu ${ }^{2}$, S Guyetant ${ }^{2}$ and A Scorilas ${ }^{*}$ \\ ${ }^{1}$ Department of Biochemistry and Molecular Biology, University of Athens, Panepistimiopolis, 15701 Athens, Greece and ${ }^{2}$ Centre \\ d'Etude des Pathologies Respiratoires, INSERM UMR1100, F-37032 Tours, France
}

Background: MicroRNA expression signatures can promote personalised care for non-small cell lung cancer (NSCLC) patients. Our aim was to evaluate the previously unexplored prognostic potential of miR-197, a key oncogenic molecule for NSCLC.

Methods: Total RNA isolation ( $n=124$ NSCLC and $n=21$ tumour-adjacent normal tissues), was performed using the QIAsymphony SP workstation. The quantity and quality of RNA were assessed by spectrophotometric analysis and an Agilent 2100 bioanalyzer. Polyadenylation and reverse transcription were subsequently carried out. MiR-197 expression levels were measured by qPCR, after quality control (inter-assay $\mathrm{CV}=7.8 \%$ ). Internal validation procedures were followed by assigning training and test sets and robust biostatistical analyses were performed, including bootstrap resampling.

Results: MiR-197 is associated with larger tumours $(P=0.042)$ and the squamous cell carcinoma histotype $(P=0.032)$. Interestingly, after adjusting for important prognostic indicators, miR-197 expression was identified as a novel independent predictor of unfavourable prognosis for NSCLC patients $(H R=1.97,95 \% \mathrm{Cl}=1.10-3.38, P=0.013)$. We also demonstrate that miR-197 retains its prognostic performance in both early-stage I $(P=0.045)$ and more advanced-stage individuals $(P=0.036)$.

Conclusions: The cost-effective expression analysis of miR-197 could constitute a novel molecular tool for NSCLC management.

Optimal confrontation of non-small cell lung cancer (NSCLC) remains a largely unachieved objective, as the 5-year survival rate struggles to surpass 15\% (Powell et al, 2013; Reck et al, 2013). Most decisions throughout the clinical management of NSCLC are dictated by TNM staging. Surgical removal of tumours, where feasible, is the gold standard of treatment (Peters et al, 2012; Reck et al, 2013; Vansteenkiste et al, 2013; Johnson et al, 2014). However, even early-stage resected patients present an extremely variable oncologic outcome; this is a reflection of the large biological heterogeneity between patients who are currently erroneously categorised in the same prognostic group (Powell et al, 2013). For example, adjuvant chemotherapy has not been proven to prolong the survival of stage I patients (especially stage IA; Gadgeel et al, 2012; Reck et al, 2013; Johnson et al, 2014). Meanwhile, $\sim 30-40 \%$ of stage I NSCLC patients are expected to relapse within 5 years (Martini et al, 1995; Goodgame et al, 2008;
Zhu et al, 2010), and this illustrates a severe inability, intrinsic to TNM staging, in defining high-risk patients who should receive adjuvant chemotherapy. In advanced disease stages, an accurate prognostic indicator could guide the administration of maintenance therapy, a clinical decision that currently remains under serious controversy (Gadgeel et al, 2012; Peters et al, 2012; Johnson et al, 2014). Consequently, there is a necessity for novel molecular prognostic indicators that would enhance the conventional staging system and improve the decision-making process.

MicroRNAs (miRNAs) are regarded as a novel source of biomarkers for the majority of human malignancies (Nana-Sinkam and Croce, 2013) and NSCLC is not an exception (Vannini et al, 2013). From the very first study, conducted in 2004 by Takamizawa et al, addressing the prognostic value of let-7 in NSCLC (Takamizawa et al, 2004), up to contemporary research, miRNAs are proving to have a decisive role in lung cancer 
Table 1. The role of miR-197 in malignant and non-malignant diseases

\begin{tabular}{|c|c|}
\hline Disease & Description \\
\hline \multicolumn{2}{|l|}{ Human Malignancies } \\
\hline Lung cancer & $\begin{array}{l}\text { Oncogenic activity, through the suppression of p53-dependent apoptotic cascade, including } \\
\text { repression of NOXA and BMF genes } \\
\text { Upregulated in lung cancer compared with non-cancerous tissues } \\
\text { Upregulated in the plasma of lung cancer patients compared with controls, including stage I } \\
\text { patients compared with controls. Upregulated in the plasma of lung cancer patients with } \\
\text { metastasis compared with metastasis-free patients. Decreased plasma levels in patients that } \\
\text { respond to chemotherapy ( } n=14 \text { ) } \\
\text { Upregulated in the serum of lung cancer patients compared with controls. Downregulated in } \\
\text { the serum of lung cancer patients with metastasis compared with metastasis-free patients } \\
\text { Regulator of the tumour suppressor FUS1 in lung cancer. Elevated miR-197 expression is } \\
\text { correlated with reduced Fus1 expression in NSCLC tumour specimens } \\
\text { Serum miR-197 measurements in combination with other miRNAs are associated with } \\
\text { risk of lung cancer development and can predict the presence of aggressive disease } \\
\text { (e.g., miR-197/miR-451, miR-197/miR-660, miR-197/miR-486-5p) }\end{array}$ \\
\hline Hepatocellular carcinoma & $\begin{array}{l}\text { Upregulated in hepatocellular carcinoma }(\mathrm{HCC}) \text { tissues compared with normal hepatic tissues. } \\
\text { Downregulation of miR-197 coupled with the upregulation of the tumour metastasis suppressor } \\
\text { CD82 in HCC cells leads to the inhibition of HCC migration and invasion in vitro and in vivo. } \\
\text { Anti-miR-197 repressed lung cancer metastatic nodes in nude mice }\end{array}$ \\
\hline Pancreatic cancer & $\begin{array}{l}\text { Upregulated in invasive ductal adenocarcinoma tissues compared with normal pancreas and } \\
\text { intraductal papillary mucinous adenoma. Enhances cellular migration and invasion of pancreatic } \\
\text { cancer cells and promotes EMT and metastasis by targeting p120 catenin } \\
\text { Upregulated in pancreatic cancerous compared with normal tissue parts }\end{array}$ \\
\hline Thyroid cancer & $\begin{array}{l}\text { Upregulated in tissue samples of oncocytic follicular carcinomas compared with normal thyroid } \\
\text { tissue. Upregulated in thyroid tumours compared with hyperplastic nodules } \\
\text { Upregulated in tissue samples of follicular thyroid carcinoma (FTC) compared with follicular } \\
\text { adenoma. Contribution to FTC carcinogenesis. Inhibition of miR-197 in thyroid cancer cells } \\
\text { induces growth arrest } \\
\text { Expression of miR-197 along with other miRNAs combined in a predictive model can } \\
\text { differentiate malignant from benign indeterminate thyroid lesions }\end{array}$ \\
\hline Ovarian cancer & Upregulated in recurrent compared with primary ovarian cancer \\
\hline Cervical carcinoma & Upregulated in cervical carcinoma tissues compared with atypical dysplasia \\
\hline Tongue SCC & Upregulated in cancerous compared with paired normal tissue parts \\
\hline Prostate cancer & Upregulated in prostate cancerous compared with normal tissues \\
\hline Breast cancer (male) & Upregulated in male breast cancer tissues compared with gynaecomastia specimens \\
\hline Oral cancer & $\begin{array}{l}\text { Downregulation of miR-197 (tissue and saliva) levels in progressing low-grade dysplasia } \\
\text { leukoplakia }\end{array}$ \\
\hline Gastric cancer & Downregulated in gastric cancerous compared with paired normal tissue \\
\hline Colon cancer & Downregulation in colon cancer cells in vitro upon administration of chemotherapeutics \\
\hline Breast cancer & Downregulated upon progestins administration \\
\hline Malignant astrocytomas & $\begin{array}{l}\text { Serum levels decreased in patients with malignant astrocytomas compared with normal controls } \\
\text { and with astrogliosis samples }\end{array}$ \\
\hline Anaplastic large-cell lymphoma & $\begin{array}{l}\text { Upregulation that differentiates anaplastic lymphoma kinase-negative }(-) \text { anaplastic large-cell } \\
\text { lymphomas from other peripheral T-cell lymphomas }\end{array}$ \\
\hline Osteosarcoma & Downregulated in Apurinic/apyrimidinic endonuclease1-knockdown osteosarcoma cells \\
\hline
\end{tabular}

References

Fiori et al (2014)

Yanaihara et al (2006)

Zheng et al (2011)

Abd-El-Fattah et al (2013)

Du et al (2009)

Boeri et al (2011)

Dai et al (2014)

Hamada et al (2013)

Volinia et al (2006)

Nikiforova et al (2008)

Weber et al (2006)

Keutgen et al (2012)

Laios et al (2008)

Pereira et al (2010)

Wong et al (2008)

Volinia et al (2006)

Lehmann et al (2010)

Yang et al (2013b)

Li et al (2011)

Zhou et al (2010)

Rivas et al (2012)

Yang et al (2013a)

Liu et al (2013)

Dai et al (2013)

\section{Non-malignant diseases}

\section{Pneumonia}

Tuberculosis

Uterine leiomyomas

Type 2 diabetes

Upregulated in serum of patients with pneumonia compared with controls

Upregulated in serum of patients with pulmonary tuberculosis compared with controls

Downregulated in human uterine leiomyomas compared with matched myometrium

Downregulated in the plasma of prevalent type 2 diabetes patients compared with

control samples

Myocardial infarction

Metabolic syndrome

Serum miR-197 levels are inversely associated with disease risk

Expression in exosomes is associated with dyslipidemia in metabolic syndrome

MiR-197 measured in serum is associated with decreased metabolic syndrome risk

Multiple sclerosis

Alzheimer's disease

Downregulation in peripheral blood T cells from MS patients compared with controls

Upregulated in Alzheimer disease brain parenchyma, and cerebrospinal fluid

Neural tube defects (NTDs)

An SNP (rs7646) affecting miR-197 binding affinity to the MTHFD1L (methylenetetrahydrofolate dehydrogenase (NADP + dependent) 1-like) 3' UTR is associated with increased risk of NTDs

Steatohepatitis

miR-197 measured in adipose tissue is associated with pericellular fibrosis in NASH patients

Upregulated in placenta tissues from patients with preeclampsia compared with normotensive placenta

Upregulated in the serum of varicella patients from healthy controls and other microbial infections

Varicella-zoster virus infection

Downregulated gradually in peripheral blood mononuclear cells of hepatitis B-infected patietns with disease symptoms deterioration; possibly targets IL-18

Hepatitis $B$ virus infection

Decreased circulating levels in primary biliary cirrhosis compared with healthy controls and hepatitis

Biliary cirrhosis

Downregulated in psoriatic compared with normal skin tissues and psoriatic uninvolved skin tissue parts

Psoriasis

Upregulated in microphthalmia-associated transcription factor knocked down melanocytes

Abd-El-Fattah et al (2013)

Abd-El-Fattah et al (2013)

Wang et al (2007)

Zampetaki et al (2010)

Zampetaki et al (2012)

Karolina et al (2012)

Zhou et al (2014)

Jernas et al (2013)

Maes et al (2009)

Minguzzi et al (2014)

Estep et al (2010)

Choi et al (2013)

Qi et al (2014)

Chen et al (2013)

Ninomiya et al (2013)

Lerman et al (2011)

Wang et al (2012) 
pathobiology and to represent promising molecular markers for NSCLC prognosis (Boeri et al, 2012; Shen and Jiang, 2012; Vannini et al, 2013; Liloglou et al, 2014).

MicroRNA 197 (miR-197) represents a molecule that is associated with a wide range of pathologic conditions ranging from non-neoplastic diseases (e.g., type 2 diabetes, myocardial infarction, metabolic syndrome) to major human malignancies (e.g., NSCLC, hepatocellular carcinoma, pancreatic cancer, thyroid cancer; detailed overview in Table 1). Interestingly, a recent study by Fiori et al (2014) provided strong evidence that miR-197 is a functional oncomiR with a central role in NSCLC pathogenesis, mediated through the suppression of the p53-dependent apoptotic cascade. MiR-197 targeting is therapeutically relevant, as it can inhibit tumour growth in vivo (Fiori et al, 2014). Previous studies had also shown that miR-197 regulates the expression of the tumour suppressor FUS1 in NSCLC and is upregulated in the tissue and plasma of lung cancer patients (Du et al, 2009; Zheng et al, 2011).

Consequently, based on: (i) the robust association between miR197 and NSCLC pathogenesis/progression (Du et al, 2009; Fiori et al, 2014), (ii) the key oncogenic role of miR-197 in aggressive human malignancies (Hamada et al, 2013; Dai et al, 2014) and (iii) the diagnostic capacity of circulating miR-197 in lung cancer (Zheng et al, 2011; Abd-El-Fattah et al, 2013), we aimed to evaluate the previously unexplored potential of this lung oncomiR as a novel prognostic tissue biomarker for NSCLC.

\section{MATERIALS AND METHODS}

Collection, storage and characteristics of the NSCLC tissue specimens. A total of 124 primary NSCLC tissue specimens, as well as 21 samples from normal tumour-adjacent tissue parts, were collected from surgically resected patients with early and advanced disease stages at the Trousseau Hospital, Tours, France, between 2006 and 2011. The mean age \pm s.e. of patients was $65.3 \pm 0.94$. No neoadjuvant treatment was administered in these patients. All the participating patients gave their informed consent before the initiation of this study, which was designed and performed following the ethical guidelines of the Helsinki Declaration and the French bioethical committees.

Tissue samples were selected and reviewed by an experienced pathologist. The non-cancerous parts had a distance of at least $3 \mathrm{~cm}$ from the tumour. Upon selection, the samples were quickly frozen under liquid nitrogen and stored for further analysis at $-80^{\circ} \mathrm{C}$. Histological diagnosis and tumour grading was established according to the World Health Organisation classification of lung tumours. Tumour staging was performed in agreement with the seventh lung cancer TNM classification and staging system. Detailed clinical and pathological characteristics of the patients collective are described in Table 2.

Tissue homogenisation, total RNA isolation, polyadenylation and reverse transcription. The Tissue-Tek O.C.T. (Sakura Finetek Europe, Alphen aan den Rijn, The Netherlands) and a cryotome (Thermo Scientific Inc., Waltham, MA, USA) platform were used for sectioning the fresh frozen NSCLC tissue samples $(\leqslant 50 \mathrm{mg}$ tissue per sample). Consequently, the tissue parts were lysed in $430 \mu \mathrm{l}$ lysis buffer (RLT Plus, Qiagen Inc., Valencia, CA, USA) with $143 \mu \mathrm{M} \beta$-mercaptoethanol and, upon complete homogenisation, were centrifuged for $1 \mathrm{~min}$ at maximum speed. Total RNA was isolated from the resulting supernatant using QIAsymphony SP workstation and the RNA CT 400 protocol (Qiagen Inc.). To avoid DNA contamination, digestion with DNAse I was also performed. The quantity, quality and purity of the resulting RNA were thoroughly assessed by a NanoDrop 2000c spectrophotometer (Thermo Scientific Inc.) and an Agilent 2100 bioanalyzer. Only
Table 2. Clinicopathological and demographic characteristics of the NSCLC patients

\begin{tabular}{|l|r|}
\hline Variable & N (\%) \\
\hline Gender & $100(80.6)$ \\
\hline Male & $24(19.4)$ \\
Female &
\end{tabular}

\section{Smoking status}

\begin{tabular}{|l|r|}
\hline Non-smoker & $12(9.8)$
\end{tabular}

Smoker

$x$

Pack-years

\begin{tabular}{|l|r|}
\hline$<21$ & $14(12.8)$ \\
$21-49$ & $59(54.1)$ \\
$>49$ & $36(33.0)$
\end{tabular}

$>49$

Histotype

Squamous cell carcinoma

Adenocarcinoma

Other

$111(90.2)$

1

\section{COPD}

No
Yes

$\mathrm{x}$

Differentiation

Poorly differentiated

Moderately/well differentiated

$x$

Tumour size

$\leqslant 3 \mathrm{~cm}$

$>3 \mathrm{~cm}$

$36(29.0)$

$88(71.0)$

\section{Lymph node}

\section{Negative}

Positive

$x$

Metastasis

Negative

Positive

70 (56.9)

$53(43.1)$

1

\section{pTNM stage}

IA

IB

IIA

IIB

IIIA

IIIB

IV

$\mathrm{X}$

\section{Deceased}

\begin{tabular}{|l|r|}
\hline No & $63(50.8)$ \\
\hline$Y e s$ & $61(49.2)$ \\
\hline
\end{tabular}

Yes

$61(49.2)$

Adjuvant chemotherapy

No

Yes

$65(52.8)$

$34(27.6)$

$10(8.1)$

$12(9.8)$

$23(18.7)$

$5(4.1)$

$18(14.6)$

1

Abbreviations: $\mathrm{COPD}=$ chronic obstructive pulmonary disease; $\mathrm{NSCLC}=$ non-small cell lung cancer; PTNM $=$ postsurgical pathologic tumour node metastasis $;=$ unknown.

intact RNA samples with RIN $>6$ were considered for downstream applications.

Polyadenylation and reverse transcription of total RNA, including miRNAs, was performed as previously described (Mavridis et al, 2013). In brief, $500 \mathrm{ng}$ of RNA was polyadenylated in the presence of ATP $(800 \mu \mathrm{M})$ by $1 \mathrm{U}$ of E. coli Poly(A) Polymerase in the reaction buffer supplied by the manufacturer (New England Biolabs Inc., Ipswich, MA, USA) at $37^{\circ} \mathrm{C}$ for $60 \mathrm{~min}$, followed by an enzyme inactivation step at $65^{\circ} \mathrm{C}$ for $10 \mathrm{~min}$. Immediately after that, the polyadenylated RNA was 
reverse transcribed into first-strand $\mathrm{cDNA}$ in a $20 \mu \mathrm{l}$ reaction containing the reaction buffer of the manufacturer, $100 \mathrm{U}$ M-MLV reverse transcriptase in the reaction, $20 \mathrm{U}$ RNaseOUT recombinant ribonuclease inhibitor (Invitrogen, Carlsbad, CA, USA) and $0.25 \mu \mathrm{M}$ poly(T) adapter (5'-GCGAGCACAGAATTAATACGACTCAC TATAGGTTTTTTTTTTTTVN- $3^{\prime}$ ) at $37^{\circ} \mathrm{C}$ for $60 \mathrm{~min}$, followed by an enzyme inactivation step at $70^{\circ} \mathrm{C}$ for $15 \mathrm{~min}$.

Quantitative PCR for miR-197 expression analysis. MiR-197-3p expression levels were quantified using a SYBR-Green-based qPCR assay in a $10-\mu$ l reaction, which was run in duplicates in 96-well fast reaction plates (Applied Biosystems, Carlsbad, CA, USA). The reactions consisted of Kapa SYBR Fast Universal qPCR Master Mix (Kapa Biosystems, Wilmington, MA, USA) including Rox Low passive reference dye, a specific miR-197-3p- (5'-CACCACCT TCTCCACCCA- $\left.3^{\prime}\right)$ or a SNORD48- (5'-TGATGATGACCCCAG GTAACTCT $\left.-3^{\prime}\right)$ specific forward primer and a universal reverse primer (5'-GCGAGCACAGAATTAATACGAC-3'), all at a final concentration of $200 \mathrm{~nm}$, as well as $1 \mathrm{ng}$ of cDNA as template. The sizes of the miR-197 and SNORD48 amplicons were 62 and $105 \mathrm{bp}$, respectively. The qPCR reactions took place in a 7500 Fast RealTime PCR System (Applied Biosystems) using the following rapid cycling thermal protocol: a 3-min polymerase activation step at $95^{\circ} \mathrm{C}$ and 40 cycles of denaturation - annealing/extension steps at $95^{\circ} \mathrm{C}$ for $3 \mathrm{~s}-60^{\circ} \mathrm{C}$ for $30 \mathrm{~s}$. The melting curve analysis protocol followed immediately after. Each run included a no-template control. MiR-197 expression levels were normalised to the endogenous reference control SNORD48 using the formula $\Delta C_{\mathrm{T}}=$ $C_{\mathrm{T}}^{\mathrm{miR}-197}-C_{\mathrm{T}}^{\mathrm{SNORD} 48}$. To allow inter-run comparisons, the same designated cancerous sample (calibrator) was included in all qPCR runs. MiR-197 relative quantification (RQ) expression units were calculated relatively to the calibrator via the formula $\mathrm{RQ}=2^{-\Delta \Delta C \mathrm{~T}}$, where $\Delta \Delta C_{\mathrm{T}}=\Delta C_{\mathrm{T}}^{\text {sample }}-\Delta C_{\mathrm{T}}^{\text {calibrator }}$, by the 7500 software v.2.06 (Applied Biosystems).

Quality control of the developed qPCR method. The developed qPCR method went through quality control to verify its specificity, sensitivity and reproducibility. To test the specificity of the reactions, melting curve analysis and agarose gel electrophoresis were performed (Supplementary Figure S1). The presence of a unique peak in the melting curve and a unique band detected after $3.0 \%$ agarose gel electrophoreses corroborated that a single specific amplicon was produced for each case throughout the qPCR reactions.

We also assayed a series of negative control samples, including no-template controls, enzyme-negative controls (reverse transcriptase, poly(A)polymerase), as well as DNA template controls, all of which failed to generate a detectable $C_{\mathrm{T}}$ value.

Standard curves were performed for both the endogenous and target molecules, by using a series of cDNA dilutions covering 5 orders of magnitude $\left(r^{2}=0.999\right.$ for SNORD48 and $r^{2}=0.998$ for miR-197). PCR efficiencies were calculated using the slopes of the standard curves equal to 95\% for SNORD48 and 100\% for miR-197 (Supplementary Figure S1); the presence of similar qPCR efficiencies that are both under the acceptable range allows the use of the comparative $\mathrm{C}_{\mathrm{T}}$ method and excludes any PCR inhibition.

The method's reproducibility was assessed by analysing common samples $(n=7)$ in different qPCR runs and calculating the coefficient of variation from duplicate measurements (Jones and Payne, 1997). The inter-assay CV was found to be $7.8 \%$.

Biostatistical analyses - internal validation. Spearman's correlation analysis was used to analyse the associations between the continuous variables of the study. The analysis of differences in miR-197 expression levels between distinct groups of NSCLC patients was performed via the Mann-Whitney $U$-test or the Jonckheere-Terpstra test, where applicable. Paired samples analysis was conducted according to Wilcoxon signed-rank test.
The X-tile algorithm (Camp et al, 2004) was used to classify patients into miR-197-high- and miR-197-low-expression groups. More precisely, X-tile was utilised to select an optimal cutoff point while correcting for the use of minimum $P$-value statistics. Two robust methods of $P$-value correction were used that produced a cutoff with minimal chance of type I errors: (i) the MillerSiegmund $P$-value correction and (ii) the Monte-Carlo simulations by cross-validation and the corrected $P$-value approaches based on 1000 random populations. Internal validation was also performed by using the X-tile option for automatically generating random training and validation cohorts, finding the optimal cutoff point in the training set and applying this cutoff to the validation cohort; a similar procedure was also followed by creating random training and validation sets via the SPSS software. All the aforementioned methods produced the same optimal cutoff point, that is, $0.635 \mathrm{RQ}$ units of miR-197 expression (61st percentile).

After establishing and internally validating the robustness of the selected cutoff, survival analysis was performed by generating the Kaplan-Meier overall survival (OS) curves to evaluate the prognostic potential of miR-197 expression for NSCLC patients. Cox regression models were developed at the univariate and multivariate levels. Multivariate Cox regression was performed with the purpose of testing for independence of the miR-197driven prognostic information, adjusting for potentially confounding variables via a standardised and a final model. The standardised model included the marker under evaluation (miR197) along with standard prognostic variables (tumour size, nodal status, pTNM stage, differentiation, histotype), as well as typical patient demographic variables (age and gender); this standardised model can facilitate the comparison of the prognostic performance of miR-197 across the present and future studies. The final multivariate model included the variables that were found to be robustly associated with OS in univariate analysis at a statistically significant level (i.e., miR-197, pTNM stage and differentiation status). The robustness of all the above-mentioned models was validated by the bootstrap approach. Random sampling was performed with replacement, producing 1000 bootstrap samples; the bias corrected and accelerated approach was followed for the calculation of $95 \%$ confidence interval (CI).

We then followed a complementary statistical approach, based on the stratification of patients into subgroups, and the application of the Kaplan-Meier survival analyses for miR-197 expression in these groups. This approach was followed to evaluate the prognostic performance of miR-197 in meaningful subgroups of patients and irrespective of different treatments.

All the aforementioned statistical analyses were performed using the X-tile v3.6.1 (Yale University, New Haven, CT, USA), SPSS Statistics v20.0 (IBM Corp., Armonk, NY, USA) and MedCalc v.12.5 (MedCalc Software, Ostend, Belgium) software. Two-tailed tests were used and $P$-values $<0.05$ were adapted for statistical significance.

\section{RESULTS}

The expression of miR-197 in NSCLC tissues is associated with larger tumour size, and squamous cell carcinoma tumours. By analysing 21 cancerous and tumour-adjacent normal tissue pairs, no statistically significant difference was observed regarding miR-197 expression $(P=0.357)$. The expression levels of miR-197 in the 124 NSCLC tissue samples analysed ranged from 0.159 to 2.46 RQ units, with a median value of 0.512 and a mean \pm s.e. $=0.618 \pm 0.035$.

The expression of miR-197 in cancer was positively associated with tumour size, as it was increased in patients harbouring tumours $>3 \mathrm{~cm}$ compared with patients with $\leqslant 3 \mathrm{~cm}$ tumours $(P=0.042)$. MiR-197 levels were also elevated in squamous cell 

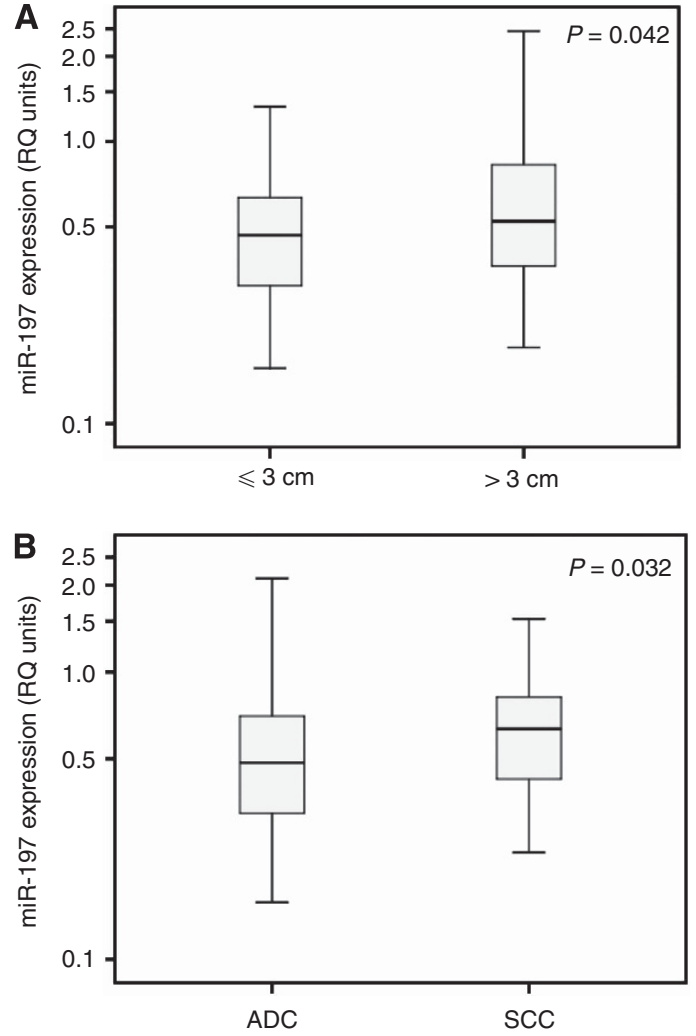

Figure 1. Distribution of miR-197 expression in NSCLC tissues. Distribution of miR-197 expression in NSCLC tissues of different tumour size (A) and histotype (B). ADC = adenocarcinoma, $\mathrm{SCC}=$ squamous cell carcinoma. P-value calculated by the Mann-Whitney $U$-test. $y$ axis is in logarithmic scale. Bold lines represent the median value.

carcinoma compared with adenocarcinoma ( $P=0.032$; Figure 1$)$. A weak, positive correlation was also observed between the expression levels of miR-197 and patients' age $\left(r_{\mathrm{s}}=0.178\right.$, $P=0.048$ ), whereas no significant associations were observed between miR-197 expression and pTNM stage $(P=0.496)$, tumour differentiation $(P=0.141)$, lymph node status $(P=0.951)$, metastasis $(P=0.910)$, smoking status $(P=0.371)$, pack-years $(P=0.826)$, the presence of chronic obstructive pulmonary disease $(P=0.589)$ or gender $(P=0.093)$.

Stratification to high- and low-risk groups based on miR-197 expression: selection of an optimal cutoff value and internal validation. An appropriate cutoff (equal to $0.635 \mathrm{RQ}$ units) that was able to effectively stratify our cohort, with respect to OS probabilities, was selected while correcting the chance of type I errors (Miller-Siegmund $P=0.022$ ). Monte-Carlo simulations in 1000 random populations resulted in the same, statistically significant results (cross-validation $P=0.027$, Monte-Carlo corrected $P=0.031$ ). The aforementioned cutoff value was identified in the X-tile randomly generated training cohort as optimal $(P=0.034)$ and then its validity was confirmed in the validation cohort $(P=0.012)$. The same results were obtained by creating random training and validation cohorts via SPSS (optimal cutoff $=0.635, P=0.030$ for the training and $P=0.004$ for the validation cohort, according to the Kaplan-Meier analysis).

MiR-197 is robustly associated with adverse oncologic outcome. Complete follow-up data regarding the OS of NSCLC patients were available for the whole cohort $(n=124)$. Median follow-up time was 27.5 months (1.0-81 months); median follow-up in patients still alive at the time of analysis was 40 months (14-81 months).

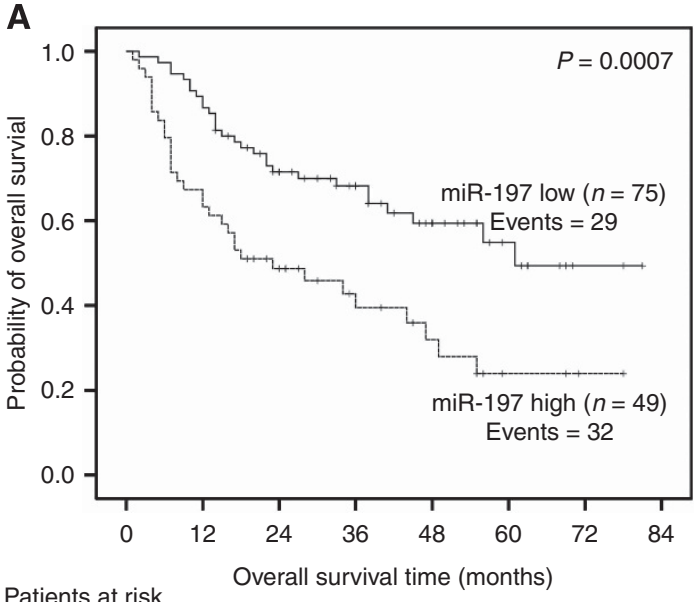

$\begin{array}{lllllllll}\begin{array}{c}\text { miR-197 } \\ \text { low }\end{array} & 75 & 65 & 47 & 33 & 18 & 10 & 2 & 0 \\ \begin{array}{c}\text { miR-197 } \\ \text { high }\end{array} & 49 & 31 & 20 & 12 & 8 & 3 & 1 & 0\end{array}$

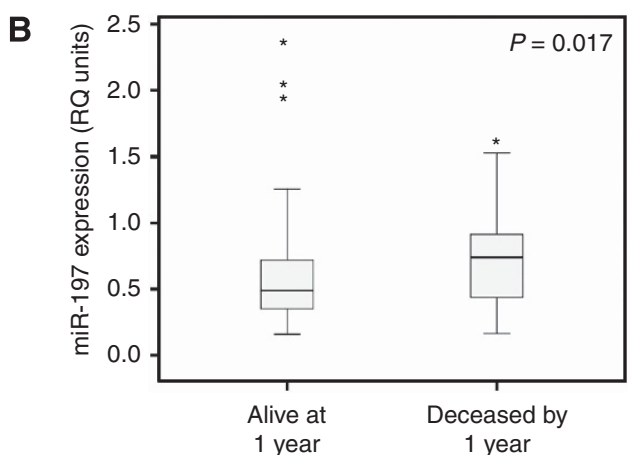

Figure 2. Association of miR-197 expression with unfavourable prognosis in the whole cohort of NSCLC patients. (A) Kaplan-Meier OS curves for the whole cohort of NSCLC patients, classified as miR197-high and miR-197-low. P-value calculated by the log-rank test. (B) MiR-197 expression levels in NSCLC patients deceased by 1 year and alive at 1 year post surgery. P-value calculated by the Mann-Whitney $U$-test. Bold lines represent the median value. *Outliers.

As indicated by the Kaplan-Meier survival analysis, patients categorised as miR-197-high clearly presented $(P=0.0007)$ a worse OS course compared with the miR-197-low ones (Figure 2A). The median survival time for miR-197-low individuals was 61 months, which is in striking difference with the corresponding period of 23 months for miR-197-high patients. Furthermore, when focusing on the 1-year survival time point, it was demonstrated that miR-197 levels were considerably higher among the deceased patients (median $=0.740$ RQ units) by 1 year compared with the survivors (median $=0.490 \mathrm{RQ}$ units) at 1 year $(P=0.017$; Figure $2 \mathrm{~B})$.

The above-mentioned prognostic potential of miR-197 was corroborated $(P=0.001)$ by univariate Cox proportional hazard regression analysis with bootstrap resampling. Patients stratified as miR-197-high were 2.31 times more likely $(95 \% \mathrm{CI}=1.44-3.73)$ to die compared with miR-197-low ones. As expected, advanced pTNM stage $(\mathrm{HR}=1.89,95 \% \mathrm{CI}=1.21-3.23, P=0.011)$, and poor tumour differentiation $(\mathrm{HR}=2.12,95 \% \mathrm{CI}=1.24-3.84$, $P=0.006$ ), also emerged as significant indicators of adverse oncologic outcome (Table 3).

MiR-197: a novel independent predictor of unfavourable prognosis for NSCLC patients. By using multivariate Cox 
Table 3. Univariate and multivariate Cox logistic regression analyses for the prediction of NSCLC patients' OS course

\begin{tabular}{|c|c|c|c|c|c|c|}
\hline Variable & HR & $95 \% \mathrm{Cl}^{\mathrm{a}}$ & $P$-value & HR & $95 \% \mathrm{Cl}^{\mathrm{a}}$ & $P$-value \\
\hline & \multicolumn{3}{|c|}{ Univariate } & \multicolumn{3}{|c|}{ Multivariate } \\
\hline \multicolumn{7}{|l|}{ miR-197 } \\
\hline $\begin{array}{l}\text { Low } \\
\text { High }\end{array}$ & $\begin{array}{l}1.00 \\
2.31\end{array}$ & $1.44-3.73$ & 0.001 & $\begin{array}{l}1.00 \\
2.52^{b} \\
1.97^{c}\end{array}$ & $\begin{array}{l}1.23-6.21^{b} \\
1.10-3.38^{c}\end{array}$ & $\begin{array}{l}0.007^{b} \\
0.013^{c}\end{array}$ \\
\hline \multicolumn{7}{|l|}{ Tumour size } \\
\hline $\begin{array}{l}\leqslant 3 \mathrm{~cm} \\
>3 \mathrm{~cm}\end{array}$ & $\begin{array}{l}1.00 \\
1.79\end{array}$ & $0.963-3.89$ & 0.069 & $\begin{array}{l}1.00 \\
1.98^{b}\end{array}$ & $0.905-5.93^{b}$ & $0.086^{b}$ \\
\hline \multicolumn{7}{|l|}{ Nodal status } \\
\hline $\begin{array}{l}\text { Lymph node negative } \\
\text { Lymph node positive }\end{array}$ & $\begin{array}{l}1.00 \\
1.51\end{array}$ & $0.922-2.62$ & 0.100 & $\begin{array}{l}1.00 \\
0.475^{b}\end{array}$ & $0.162-1.43^{b}$ & $0.096^{b}$ \\
\hline \multicolumn{7}{|l|}{ pTNM stage } \\
\hline II-IV & $\begin{array}{l}1.00 \\
1.89\end{array}$ & $1.21-3.23$ & 0.011 & $\begin{array}{l}1.00 \\
2.83^{b} \\
1.73^{c}\end{array}$ & $\begin{array}{l}1.08-8.69^{b} \\
0.978-3.36^{c}\end{array}$ & $\begin{array}{l}0.014^{b} \\
0.065^{c}\end{array}$ \\
\hline \multicolumn{7}{|l|}{ Differentiation } \\
\hline $\begin{array}{l}\text { Moderately/well } \\
\text { Poor }\end{array}$ & $\begin{array}{l}1.00 \\
2.12\end{array}$ & $1.24-3.85$ & 0.006 & $\begin{array}{l}2.20^{b} \\
1.74^{c}\end{array}$ & $\begin{array}{l}1.09-5.52^{b} \\
0.942-3.55^{c}\end{array}$ & $\begin{array}{l}0.023^{b} \\
0.054^{c}\end{array}$ \\
\hline \multicolumn{7}{|l|}{ Histotype } \\
\hline $\begin{array}{l}\mathrm{SCC} \\
\mathrm{ADC}\end{array}$ & $\begin{array}{l}1.00 \\
1.11\end{array}$ & $0.654-1.97$ & 0.674 & $1.19^{b}$ & $0.593-2.46^{b}$ & $0.578^{b}$ \\
\hline Age (continuous) & 0.989 & $0.967-1.01$ & 0.352 & $0.977^{b}$ & $0.951-1.01^{b}$ & $0.077^{b}$ \\
\hline \multicolumn{7}{|l|}{ Gender } \\
\hline $\begin{array}{l}\text { Male } \\
\text { Female }\end{array}$ & $\begin{array}{l}1.00 \\
0.844\end{array}$ & $0.443-1.56$ & 0.579 & $1.102^{b}$ & $0.445-3.13^{b}$ & $0.798^{b}$ \\
\hline \multicolumn{7}{|c|}{ 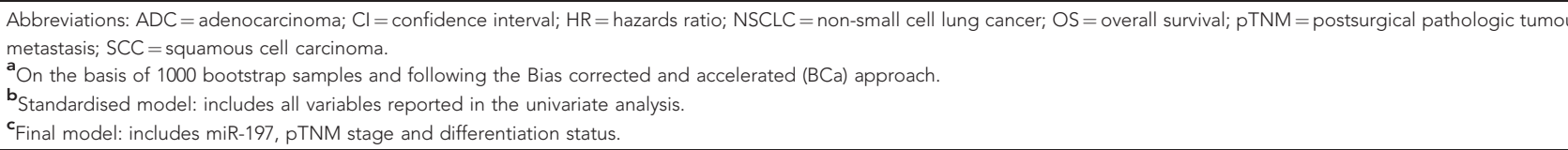 } \\
\hline
\end{tabular}

regression analysis, adjusted for standard prognostic indicators and typical demographic factors, it was demonstrated that miR-197 expression is a strong and independent predictor $(P=0.007)$ of adverse oncologic outcome $(\mathrm{HR}=2.52,95 \%$ $\mathrm{CI}=1.23-6.21)$ for NSCLC patients (Table 3). Other important predictors were pTNM stage $(\mathrm{HR}=2.83,95 \% \mathrm{CI}=1.08-8.69$, $\mathrm{P}=0.014)$ and differentiation status $(\mathrm{HR}=2.20,95 \% \mathrm{CI}=1.09$ $5.52, \mathrm{P}=0.023$; Table 3 ).

All statistically significant predictors (miR-197, tumour stage and differentiation) were included in a final model, in which only miR-197 retained its robust prognostic performance $(\mathrm{HR}=1.97$, $95 \% \mathrm{CI}=1.10-3.38, P=0.013$; Table 3 ).

Tissue miR-197 expression is associated with unfavourable prognosis in subgroups of NSCLC patients. As demonstrated in Figure 3, miR-197 expression is significantly associated with adverse oncologic outcome in both stage I $(P=0.045)$ and more advanced stages (II-IV; $P=0.036$; Figure $3 \mathrm{~A}$ and $\mathrm{B}$, respectively). These results were confirmed by univariate Cox regression, which showed that stage I patients with high miR-197 expression presented a poorer OS course compared with patients categorised as miR-197-low $(\mathrm{HR}=2.34,95 \% \mathrm{CI}=0.974-5.64, P=0.044)$. For stage II-IV patients, the corresponding HR value was $1.93(95 \%$ $\mathrm{CI}=1.06-3.90, P=0.038)$.

In addition, miR-197 showed a statistically significant ability for risk stratification of NSCLC patients regarding OS, irrespectively of the administration of post-operative chemotherapy $(P=0.042)$, Figure $3 \mathrm{C}$ and $\mathrm{HR}=1.95,95 \% \mathrm{CI}=0.99-4.15, P=0.048$ ) or not $(P=0.045$, Figure $3 \mathrm{D}$ and $\mathrm{HR}=2.23,95 \% \mathrm{CI}=0.935-5.47$, $P=0.045)$.

\section{DISCUSSION}

Contemporary research has proven that molecular signatures can constitute the first, yet decisive, step towards the realisation of personalised cancer care. Successful examples include the routinely used gene expression tests MammaPrint and OncotypeDx for breast cancer (Duffy and Crown, 2008) and the recently FDAapproved multifactorial biomarker panels ROMA score and OVA1 for ovarian cancer (Leung et al, 2012). Novel molecular prognostic indicators, such as miRNAs, could also aid towards enhancing the clinical management of NSCLC patients (Lin and Beer, 2012; Powell et al, 2013). The advantage of miRNAs as prognostic biomarkers include: (i) their reliable and cost-efficient quantification in specimens accompanied by invaluable clinical information such as FFPE tissues, as well as in minimal diagnostic tissue specimens from biopsies (Boeri et al, 2012; Shen and Jiang, 2012; Liloglou et al, 2014), (ii) the enhanced clinical information regarding molecular cancer pathogenesis that can derive from their expression analysis; an alteration in the expression of a single miRNA molecule usually reflects changes affecting a broad range of biological pathways (Boeri et al, 2012; Nana-Sinkam and Croce, 2013). MiRNAs are currently investigated as biomarkers for several human malignancies, including NSCLC, in $>100$ clinical trials (Nana-Sinkam and Croce, 2013).

In the present study we show that miR-197 is robustly associated with an adverse OS outcome in NSCLC patients, independently of several important prognostic indicators such as pTNM stage (Table 3). After analysing meaningful NSCLC patient subgroups, we demonstrate that miR-197 retains its predictive 
A

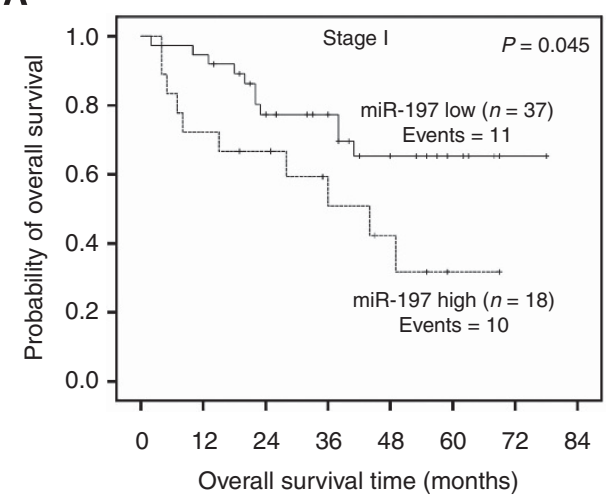

Patients at risk

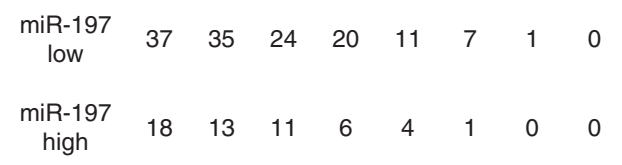

C

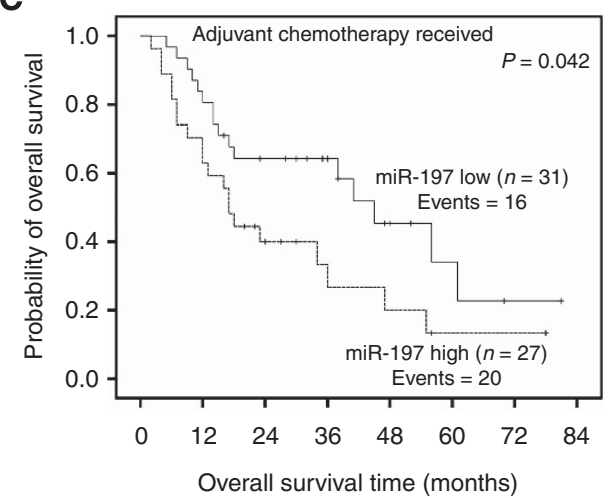

Patients at risk

$\begin{array}{ccccccccc}\begin{array}{c}\text { miR-197 } \\ \text { low }\end{array} & 31 & 25 & 18 & 11 & 5 & 3 & 1 & 0 \\ \begin{array}{c}\text { miR-197 } \\ \text { high }\end{array} & 27 & 17 & 8 & 4 & 3 & 1 & 1 & 0\end{array}$

B

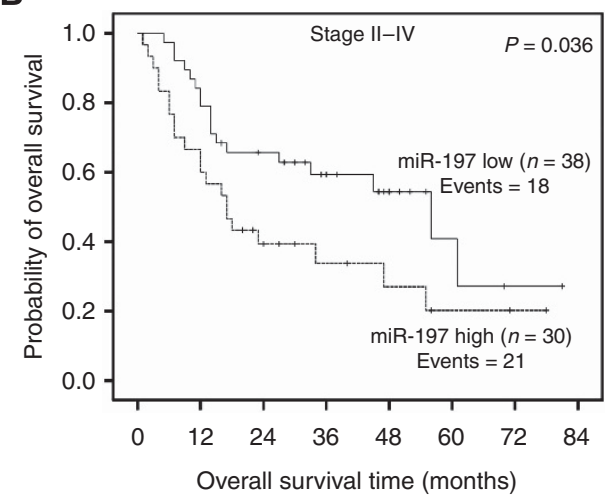

Patients at risk

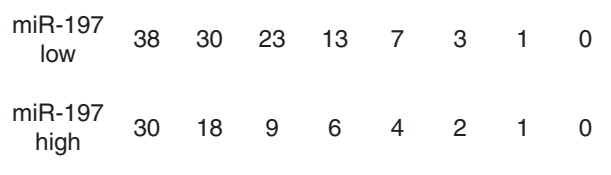

D

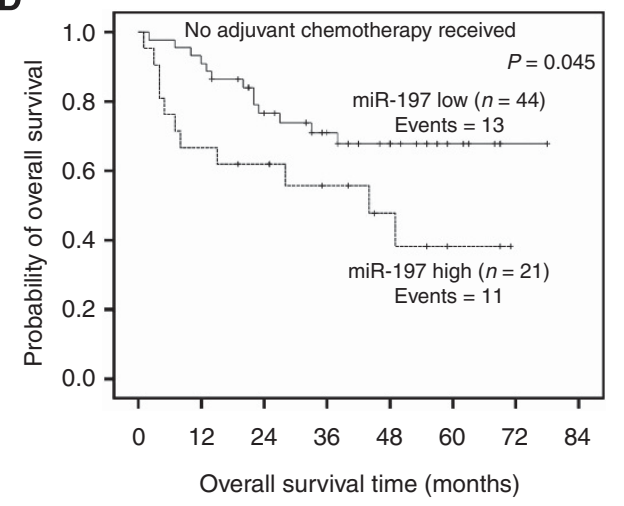

Patients at risk

$\begin{array}{ccccccccc}\begin{array}{c}\text { miR-197 } \\ \text { low }\end{array} & 44 & 40 & 29 & 22 & 13 & 7 & 1 & 0 \\ \begin{array}{c}\text { miR-197 } \\ \text { high }\end{array} & 21 & 14 & 12 & 8 & 5 & 2 & 0 & 0\end{array}$

Figure 3. Kaplan-Meier survival analyses for NSCLC patient subgroups. Stage I (A), advanced stages II-IV (B), adjuvant chemotherapy treated (C), no adjuvant chemotherapy treated (D) patients. P-values calculated by the log-rank test.

properties in stage $\mathrm{I}$, as well as in more advanced disease stages (Figure 3). Interestingly, miR-197 has already been evaluated as a circulating diagnostic marker for NSCLC; plasma and serum measurements of miR-197 can distinguish lung cancer patients from healthy individuals (Zheng et al, 2011; Abd-El-Fattah et al, 2013) and when they are used in combination with other miRNA molecules are predictive of lung cancer risk and the presence of aggressive disease (Boeri et al, 2011) (Table 1).

The apparent association between tissue miR-197 expression and adverse oncologic outcome, described in the present study, is in fine agreement with its previously reported oncogenic role in lung cancer (Du et al, 2009; Fiori et al, 2014). More precisely, it has been recently proven that miR-197 exerts its lung tumourpromoting role by inhibiting the p53 apoptotic cascade, through a mechanism that includes the suppression of NOXA and BMF genes; interestingly, in vivo experiments showed that miR-197 inhibition suppresses tumour growth and has therapeutic relevance for NSCLC (Fiori et al, 2014). A previous study had also shown that miR-197 targets the tumour suppressor FUS1 (Du et al, 2009). In addition, Yanaihara et al (2006) reported, based on microarray data, that miR-197 is upregulated in cancerous versus noncancerous lung tissues. In our study, we did not observe such an upregulation; this might be attributed to the limited sample size of non-cancerous tissues that we had available and/or the different techniques for miR-197 determination that were used between the two studies. However, we found that tissue miR-197 expression was associated with the presence of larger tumours $(P=0.042)$ and the squamous cell carcinoma histotype $(P=0.032)$. MiR-197 has also been described as oncogenic in a series of other aggressive malignancies. In hepatocellular carcinoma, miR-197 is upregulated and linked with enhanced cell migration, invasion and metastasis both in vitro and in vivo (Dai et al, 2014). In pancreatic cancer, miR-197 is upregulated and has been shown to promote cell migration, invasion, epithelial-mesenchymal transition and metastasis (Hamada et al, 2013). In thyroid cancer, the observed upregulation of miR-197 has been associated with carcinogenesis (Weber et al, 2006).

Despite following the internal validation and quality control procedures, the results of our study still require rigorous external validation though independent, larger and ideally multicentric cohorts, to comprehensively corroborate the prognostic significance of miR-197. Given the previously reported biological link between miR-197 and p53, it would be interesting to investigate if the prognostic performance of miR-197 can be improved by 
including the p53 mutation status of NSCLC patients. Considering that the $\mathrm{qPCR}$ technique that we used cannot account for tissue heterogeneity, it would be fitting to analyse, in a future study, the expression of miR-197 through in situ hybridisation to evaluate if there is any association between miR-197 staining intensity in distinct tissue parts and tumour aggressiveness and/or oncologic outcome. Another interesting perspective would be the clinical evaluation of tissue or circulating miR-197 levels as a biomarker for predicting or monitoring chemotherapy response in NSCLC.

According to our data, the cost-effective expression analysis of miR-197 at the time of diagnosis could be considered further as a novel molecular tool that could contribute to a more optimised clinical management for NSCLC patients.

\section{ACKNOWLEDGEMENTS}

We thank Professor Pascal Dumont (Tours Hospital), Valérie Gissot, Lysiane Brick, Géraldine Meunier, Alexandra Fayault and Aliette Decock-Giraudaud (CIC INSERM 1415) for their help in collecting tissues and clinical data.

\section{CONFLICT OF INTEREST}

The authors declare no conflict of interest.

\section{REFERENCES}

Abd-El-Fattah AA, Sadik NA, Shaker OG, Aboulftouh ML (2013) Differential microRNAs expression in serum of patients with lung cancer, pulmonary tuberculosis, and pneumonia. Cell Biochem Biophys 67(3): 875-884.

Boeri M, Pastorino U, Sozzi G (2012) Role of microRNAs in lung cancer: microRNA signatures in cancer prognosis. Cancer J 18(3): 268-274.

Boeri M, Verri C, Conte D, Roz L, Modena P, Facchinetti F, Calabro E, Croce CM, Pastorino U, Sozzi G (2011) MicroRNA signatures in tissues and plasma predict development and prognosis of computed tomography detected lung cancer. Proc Natl Acad Sci USA 108(9): 3713-3718.

Camp RL, Dolled-Filhart M, Rimm DL (2004) X-tile: a new bio-informatics tool for biomarker assessment and outcome-based cut-point optimization. Clin Cancer Res 10(21): 7252-7259.

Chen L, Li C, Peng Z, Zhao J, Gong G, Tan D (2013) miR-197 expression in peripheral blood mononuclear cells from hepatitis B virus-infected patients. Gut Liver 7(3): 335-342.

Choi SY, Yun J, Lee OJ, Han HS, Yeo MK, Lee MA, Suh KS (2013) MicroRNA expression profiles in placenta with severe preeclampsia using a PNA-based microarray. Placenta 34(9): 799-804.

Dai N, Zhong ZY, Cun YP, Qing Y, Chen C, Jiang P, Li MX, Wang D (2013) Alteration of the microRNA expression profile in human osteosarcoma cells transfected with APE1 siRNA. Neoplasma 60(4): 384-394.

Dai W, Wang C, Wang F, Wang Y, Shen M, Chen K, Cheng P, Zhang Y, Yang J, Zhu R, Zhang H, Li J, Zheng Y, Lu J, Zhou Y, Xu L, Guo C (2014) Anti-miR-197 inhibits migration in HCC cells by targeting KAI 1/CD82. Biochem Biophys Res Commun 446(2): 541-548.

Du L, Schageman JJ, Subauste MC, Saber B, Hammond SM, Prudkin L, Wistuba II, Ji L, Roth JA, Minna JD, Pertsemlidis A (2009) miR-93, miR98, and miR-197 regulate expression of tumor suppressor gene FUS1. Mol Cancer Res 7(8): 1234-1243.

Duffy MJ, Crown J (2008) A personalized approach to cancer treatment: how biomarkers can help. Clin Chem 54(11): 1770-1779.

Estep M, Armistead D, Hossain N, Elarainy H, Goodman Z, Baranova A, Chandhoke V, Younossi ZM (2010) Differential expression of miRNAs in the visceral adipose tissue of patients with non-alcoholic fatty liver disease. Aliment Pharmacol Ther 32(3): 487-497.

Fiori ME, Barbini C, Haas TL, Marroncelli N, Patrizii M, Biffoni M, De Maria R (2014) Antitumor effect of miR-197 targeting in p53 wild-type lung cancer. Cell Death Differ 21(5): 774-782.

Gadgeel SM, Ramalingam SS, Kalemkerian GP (2012) Treatment of lung cancer. Radiol Clin North Am 50(5): 961-974.
Goodgame B, Viswanathan A, Miller CR, Gao F, Meyers B, Battafarano RJ, Patterson A, Cooper J, Guthrie TJ, Bradley J, Pillot G, Govindan R (2008) A clinical model to estimate recurrence risk in resected stage I non-small cell lung cancer. Am J Clin Oncol 31(1): 22-28.

Hamada S, Satoh K, Miura S, Hirota M, Kanno A, Masamune A, Kikuta K, Kume K, Unno J, Egawa S, Motoi F, Unno M, Shimosegawa T (2013) miR-197 induces epithelial-mesenchymal transition in pancreatic cancer cells by targeting p120 catenin. J Cell Physiol 228(6): 1255-1263.

Jernas M, Malmestrom C, Axelsson M, Nookaew I, Wadenvik H, Lycke J, Olsson B (2013) MicroRNA regulate immune pathways in T-cells in multiple sclerosis (MS). BMC Immunol 14: 32.

Johnson DH, Schiller JH, Bunn Jr. PA (2014) Recent clinical advances in lung cancer management. J Clin Oncol 32(10): 973-982.

Jones R, Payne B (1997) Clinical Investigation and Statistics in Laboratory Medicine. ACB Venture Publications: London.

Karolina DS, Tavintharan S, Armugam A, Sepramaniam S, Pek SL, Wong MT, Lim SC, Sum CF, Jeyaseelan K (2012) Circulating miRNA profiles in patients with metabolic syndrome. J Clin Endocrinol Metab 97(12): E2271-E2276.

Keutgen XM, Filicori F, Crowley MJ, Wang Y, Scognamiglio T, Hoda R, Buitrago D, Cooper D, Zeiger MA, Zarnegar R, Elemento O, Fahey 3rd TJ (2012) A panel of four miRNAs accurately differentiates malignant from benign indeterminate thyroid lesions on fine needle aspiration. Clin Cancer Res 18(7): 2032-2038.

Laios A, O'Toole S, Flavin R, Martin C, Kelly L, Ring M, Finn SP, Barrett C, Loda M, Gleeson N, D'Arcy T, McGuinness E, Sheils O, Sheppard B, O'Leary J (2008) Potential role of miR-9 and miR-223 in recurrent ovarian cancer. Mol Cancer 7: 35.

Lehmann U, Streichert T, Otto B, Albat C, Hasemeier B, Christgen H, Schipper E, Hille U, Kreipe HH, Langer F (2010) Identification of differentially expressed microRNAs in human male breast cancer. $B M C$ Cancer 10: 109.

Lerman G, Avivi C, Mardoukh C, Barzilai A, Tessone A, Gradus B, Pavlotsky F, Barshack I, Polak-Charcon S, Orenstein A, Hornstein E, Sidi Y, Avni D (2011) MiRNA expression in psoriatic skin: reciprocal regulation of hsa-miR-99a and IGF-1R. PLoS One 6(6): e20916.

Leung F, Diamandis EP, Kulasingam V (2012) From bench to bedside: discovery of ovarian cancer biomarkers using high-throughput technologies in the past decade. Biomark Med 6(5): 613-625.

Li X, Zhang Y, Zhang H, Liu X, Gong T, Li M, Sun L, Ji G, Shi Y, Han Z, Han S, Nie Y, Chen X, Zhao Q, Ding J, Wu K, Daiming F (2011) miRNA-223 promotes gastric cancer invasion and metastasis by targeting tumor suppressor EPB41L3. Mol Cancer Res 9(7): 824-833.

Liloglou T, Bediaga NG, Brown BR, Field JK, Davies MP (2014) Epigenetic biomarkers in lung cancer. Cancer Lett 342(2): 200-212.

Lin J, Beer DG (2012) Molecular predictors of prognosis in lung cancer. Ann Surg Oncol 19(2): 669-676.

Liu C, Iqbal J, Teruya-Feldstein J, Shen Y, Dabrowska MJ, Dybkaer K, Lim MS, Piva R, Barreca A, Pellegrino E, Spaccarotella E, Lachel CM, Kucuk C, Jiang CS, Hu X, Bhagavathi S, Greiner TC, Weisenburger DD, Aoun P, Perkins SL, McKeithan TW, Inghirami G, Chan WC (2013) MicroRNA expression profiling identifies molecular signatures associated with anaplastic large cell lymphoma. Blood 122(12): 2083-2092.

Maes OC, Chertkow HM, Wang E, Schipper HM (2009) MicroRNA: implications for alzheimer disease and other human CNS disorders. Curr Genomics 10(3): 154-168.

Martini N, Bains MS, Burt ME, Zakowski MF, McCormack P, Rusch VW, Ginsberg RJ (1995) Incidence of local recurrence and second primary tumors in resected stage I lung cancer. J Thorac Cardiovasc Surg 109(1): $120-129$.

Mavridis K, Stravodimos K, Scorilas A (2013) Downregulation and prognostic performance of microRNA 224 expression in prostate cancer. Clin Chem 59(1): 261-269.

Minguzzi S, Selcuklu SD, Spillane C, Parle-McDermott A (2014) An NTD-associated polymorphism in the $3^{\prime}$ UTR of MTHFD1L can affect disease risk by altering miRNA binding. Hum Mutat 35(1): 96-104.

Nana-Sinkam SP, Croce CM (2013) Clinical applications for microRNAs in cancer. Clin Pharmacol Ther 93(1): 98-104.

Nikiforova MN, Tseng GC, Steward D, Diorio D, Nikiforov YE (2008) MicroRNA expression profiling of thyroid tumors: biological significance and diagnostic utility. J Clin Endocrinol Metab 93(5): 1600-1608.

Ninomiya M, Kondo Y, Funayama R, Nagashima T, Kogure T, Kakazu E, Kimura O, Ueno Y, Nakayama K, Shimosegawa T (2013) Distinct 
microRNAs expression profile in primary biliary cirrhosis and evaluation of miR 505-3p and miR197-3p as novel biomarkers. PLoS One 8(6): e66086.

Pereira PM, Marques JP, Soares AR, Carreto L, Santos MA (2010) MicroRNA expression variability in human cervical tissues. PLoS One 5(7): e11780.

Peters S, Adjei AA, Gridelli C, Reck M, Kerr K, Felip E (2012) Metastatic nonsmall-cell lung cancer (NSCLC): ESMO Clinical Practice Guidelines for diagnosis, treatment and follow-up. Ann Oncol 23(Suppl 7): vii56-vii64.

Powell CA, Halmos B, Nana-Sinkam SP (2013) Update in lung cancer and mesothelioma 2012. Am J Respir Crit Care Med 188(2): 157-166.

Qi Y, Zhu Z, Shi Z, Ge Y, Zhao K, Zhou M, Cui L (2014) Dysregulated microRNA expression in serum of non-vaccinated children with varicella. Viruses 6(4): 1823-1836.

Reck M, Heigener DF, Mok T, Soria JC, Rabe KF (2013) Management of non-small-cell lung cancer: recent developments. Lancet 382(9893): 709-719.

Rivas MA, Venturutti L, Huang YW, Schillaci R, Huang TH, Elizalde PV (2012) Downregulation of the tumor-suppressor miR-16 via progestinmediated oncogenic signaling contributes to breast cancer development. Breast Cancer Res 14(3): R77.

Shen J, Jiang F (2012) Applications of microRNAs in the diagnosis and prognosis of lung cancer. Expert Opin Med Diagn 6(3): 197-207.

Takamizawa J, Konishi H, Yanagisawa K, Tomida S, Osada H, Endoh H, Harano T, Yatabe Y, Nagino M, Nimura Y, Mitsudomi T, Takahashi T (2004) Reduced expression of the let-7 microRNAs in human lung cancers in association with shortened postoperative survival. Cancer Res 64(11): 3753-3756

Vannini I, Fanini F, Fabbri M (2013) MicroRNAs as lung cancer biomarkers and key players in lung carcinogenesis. Clin Biochem 46(10-11): 918-925.

Vansteenkiste J, De Ruysscher D, Eberhardt WE, Lim E, Senan S, Felip E, Peters S (2013) Early and locally advanced non-small-cell lung cancer (NSCLC): ESMO Clinical Practice Guidelines for diagnosis, treatment and follow-up. Ann Oncol 24(Suppl 6): vi89-vi98.

Volinia S, Calin GA, Liu CG, Ambs S, Cimmino A, Petrocca F, Visone R, Iorio M, Roldo C, Ferracin M, Prueitt RL, Yanaihara N, Lanza G, Scarpa A, Vecchione A, Negrini M, Harris CC, Croce CM (2006) A microRNA expression signature of human solid tumors defines cancer gene targets. Proc Natl Acad Sci USA 103(7): 2257-2261.

Wang P, Li Y, Hong W, Zhen J, Ren J, Li Z, Xu A (2012) The changes of microRNA expression profiles and tyrosinase related proteins in MITF knocked down melanocytes. Mol Biosyst 8(11): 2924-2931.

Wang T, Zhang X, Obijuru L, Laser J, Aris V, Lee P, Mittal K, Soteropoulos P, Wei JJ (2007) A micro-RNA signature associated with race, tumor size, and target gene activity in human uterine leiomyomas. Genes Chromosomes Cancer 46(4): 336-347.
Weber F, Teresi RE, Broelsch CE, Frilling A, Eng C (2006) A limited set of human MicroRNA is deregulated in follicular thyroid carcinoma. J Clin Endocrinol Metab 91(9): 3584-3591.

Wong TS, Liu XB, Wong BY, Ng RW, Yuen AP, Wei WI (2008) Mature miR-184 as potential oncogenic microRNA of squamous cell carcinoma of tongue. Clin Cancer Res 14(9): 2588-2592.

Yanaihara N, Caplen N, Bowman E, Seike M, Kumamoto K, Yi M, Stephens RM, Okamoto A, Yokota J, Tanaka T, Calin GA, Liu CG, Croce CM, Harris CC (2006) Unique microRNA molecular profiles in lung cancer diagnosis and prognosis. Cancer Cell 9(3): 189-198.

Yang C, Wang C, Chen X, Chen S, Zhang Y, Zhi F, Wang J, Li L, Zhou X, Li N, Pan H, Zhang J, Zen K, Zhang CY, Zhang C (2013a) Identification of seven serum microRNAs from a genome-wide serum microRNA expression profile as potential noninvasive biomarkers for malignant astrocytomas. Int J Cancer 132(1): 116-127.

Yang Y, Li YX, Yang X, Jiang L, Zhou ZJ, Zhu YQ (2013b) Progress risk assessment of oral premalignant lesions with saliva miRNA analysis. BMC Cancer 13: 129.

Zampetaki A, Kiechl S, Drozdov I, Willeit P, Mayr U, Prokopi M, Mayr A, Weger S, Oberhollenzer F, Bonora E, Shah A, Willeit J, Mayr M (2010) Plasma microRNA profiling reveals loss of endothelial miR-126 and other microRNAs in type 2 diabetes. Circ Res 107(6): 810-817.

Zampetaki A, Willeit P, Tilling L, Drozdov I, Prokopi M, Renard JM, Mayr A, Weger S, Schett G, Shah A, Boulanger CM, Willeit J, Chowienczyk PJ, Kiechl S, Mayr M (2012) Prospective study on circulating MicroRNAs and risk of myocardial infarction. J Am Coll Cardiol 60(4): 290-299.

Zheng D, Haddadin S, Wang Y, Gu LQ, Perry MC, Freter CE, Wang MX (2011) Plasma microRNAs as novel biomarkers for early detection of lung cancer. Int J Clin Exp Pathol 4(6): 575-586.

Zhou J, Zheng Q, Xu T, Liao D, Zhang Y, Yang S, Hu J (2014) Associations between physical activity-related miRNAs and metabolic syndrome. Horm Metab Res 46(3): 201-205.

Zhou J, Zhou Y, Yin B, Hao W, Zhao L, Ju W, Bai C (2010) 5-Fluorouracil and oxaliplatin modify the expression profiles of microRNAs in human colon cancer cells in vitro. Oncol Rep 23(1): 121-128.

Zhu CQ, Ding K, Strumpf D, Weir BA, Meyerson M, Pennell N, Thomas RK, Naoki K, Ladd-Acosta C, Liu N, Pintilie M, Der S, Seymour L, Jurisica I, Shepherd FA, Tsao MS (2010) Prognostic and predictive gene signature for adjuvant chemotherapy in resected non-small-cell lung cancer. J Clin Oncol 28(29): 4417-4424.

This work is published under the standard license to publish agreement. After 12 months the work will become freely available and the license terms will switch to a Creative Commons AttributionNonCommercial-Share Alike 4.0 Unported License.

Supplementary Information accompanies this paper on British Journal of Cancer website (http://www.nature.com/bjc) 